\title{
The Power of Programming and the EarlyNutrition Project: Opportunities for Health Promotion by Nutrition during the First Thousand Days of Life and Beyond
}

\author{
Berthold Koletzko Brigitte Brands Michael Chourdakis Simone Cramer \\ Veit Grote Christian Hellmuth Franca Kirchberg Christine Prell Peter Rzehak \\ Olaf Uhl Martina Weber \\ Division of Metabolic and Nutritional Medicine, Dr. von Hauner Children's Hospital, Ludwig Maximilian University of \\ Munich, Munich, Germany
}

\section{Key Words}

Early nutrition · Pregnancy · Infant nutrition · Metabolic programming · Developmental origins of health and disease - Obesity · Adiposity

\begin{abstract}
At The Power of Programming 2014 Conference, researchers from multiple disciplines presented and discussed the effects of early nutrition and other environmental cues during the first thousand days of life and beyond on the lifelong risk of noncommunicable diseases. This paper aims to summarize the concepts and some of the first achievements of the EarlyNutrition research project that initiated the conference. The EarlyNutrition consortium is a multinational, multidisciplinary research collaboration of researchers from Europe, the USA, and Australia. A focus is placed on exploration of the developmental origins of obesity, adiposity, and related health outcomes. Here we report on the first findings of experimental approaches, cohort studies, randomized clinical trials, and systematic reviews of current information, as well as position papers, which have all been developed with the
\end{abstract}

involvement of project partners. We conclude that the EarlyNutrition project has successfully established itself during the first 2 project years as a very strong platform for collaborative research on early programming effects. The first results, available already at this early stage of the project, point to great opportunities for health prevention strategies via the implementation of dietary and lifestyle modifications, with large effect sizes. Further results are expected which should support improved recommendations and related policies for optimized nutrition and lifestyle choices before and during pregnancy, in infancy, and in early childhood.

(c) 2014 S. Karger AG, Basel

\section{The Power of Programming 2014 Conference}

This volume of Annals of Nutrition and Metabolism presents a series of papers focusing on early metabolic programming during periods of developmental plasticity and related effects on adult health and disease. Particular attention is given to the developmental origins of obesity, adiposity, and related conditions. These publications

\section{KARGER}

E-Mail karger@karger.com

www.karger.com/anm
(C) 2014 S. Karger AG, Basel

$0250-6807 / 14 / 0644-0187 \$ 39.50 / 0$
Berthold Koletzko, Prof of Paediatrics

Division of Metabolic and Nutritional Medicine

Dr. von Hauner Children's Hospital, Ludwig Maximilian University of Munich

Lindwurmstrasse 4, DE-80337 München (Germany)

E-Mail office.koletzko@med.uni-muenchen.de 
Table 1. Partner institutions participating in the EarlyNutrition project

\begin{tabular}{|c|c|}
\hline \multicolumn{2}{|l|}{ Europe } \\
\hline University of Munich (coordinator) & Germany \\
\hline Kings College London & $\mathrm{UK}$ \\
\hline Medical University of Graz & Austria \\
\hline Statens Serum Institute & Denmark \\
\hline University of Murcia & Spain \\
\hline University of Nottingham & UK \\
\hline Norwegian Institute of Public Health & Norway \\
\hline University College Dublin & Ireland \\
\hline University of Amsterdam & The Netherlands \\
\hline Rovira i Virgili University & Spain \\
\hline Leiden University Medical Center & The Netherlands \\
\hline University of Southampton & UK \\
\hline Erasmus University Medical Center & The Netherlands \\
\hline University of Granada & Spain \\
\hline University of Copenhagen & Denmark \\
\hline Medical University of Warsaw & Poland \\
\hline University of Cambridge & UK \\
\hline University College Cork & Ireland \\
\hline Università degli Studi di Milano & Italy \\
\hline The Children’s Memorial Health Institute & Poland \\
\hline National and Kapodistrian University of Athens & Greece \\
\hline Centre Hospitalier Chrétien - Liège & Belgium \\
\hline Medscinet AB & Sweden \\
\hline Service XS BV & The Netherlands \\
\hline Biolution $\mathrm{GmbH}$ & Austria \\
\hline Danone Research BV & The Netherlands \\
\hline Beneo GmbH & Germany \\
\hline Abbott Nutrition Research & Spain \\
\hline \multicolumn{2}{|l|}{ USA } \\
\hline University of California & Irvine, Calif., USA \\
\hline Harvard Medical School & Boston, Mass., USA \\
\hline University of Texas Health Sciences Center & San Antonio, Tex., USA \\
\hline \multicolumn{2}{|l|}{ The MetroHealth System, Case Western Reserve } \\
\hline University School of Medicine & Cleveland, Ohio, USA \\
\hline \multicolumn{2}{|l|}{ Australia } \\
\hline \multicolumn{2}{|l|}{ Telethon Institute for Child Health Research, } \\
\hline \multicolumn{2}{|l|}{ Murdoch Children's Research Institute, } \\
\hline University of Melbourne & Melbourne, Vic., Australia \\
\hline University of Adelaide & Adelaide, S.A., Australia \\
\hline
\end{tabular}

have been developed from presentations given at The Power of Programming 2014: International Conference on Developmental Origins of Adiposity and Long-Term Health, which took place on March 13-15, 2014, at the Ludwig Maximilian University of Munich, Germany. The meeting was attended by 540 participants from 55 countries on all 5 continents, including researchers from multiple disciplines such as basic, epidemiological, and clinical sciences, experts in public health, policy, and regulatory affairs, representatives of companies related to biomedical, dietetic, and food products and services, and many others. The presentations at this conference addressed the possible modification of the lifelong risk of noncommunicable diseases through early nutrition and other environmental cues during approximately the first thousand days from conception to early childhood, while also considering factors acting prior to conception and during later childhood. Exploration of the possible underlying mechanisms received particular attention. The aim of this paper is to summarize the concepts and some of the first achievements of the EarlyNutrition research project that initiated the conference. 
Fig. 1. Nutritional and metabolic factors acting during sensitive time periods of developmental plasticity before and after childbirth modulate cytogenesis, organogenesis, metabolic and endocrine responses, and epigenetic regulation of gene expression and thereby can induce metabolic programming of lifelong health and disease risk. Modifed from Brands and Koletzko [2].

Fig. 2. The current key hypotheses on early metabolic programming of adiposity and related diseases explored by the EarlyNutrition project include the fuel-mediated in utero hypothesis, the accelerated postnatal growth hypothesis, and the mismatch of pre- and postnatal growth trajectories hypothesis. Modified after Koletzko et al. [4].
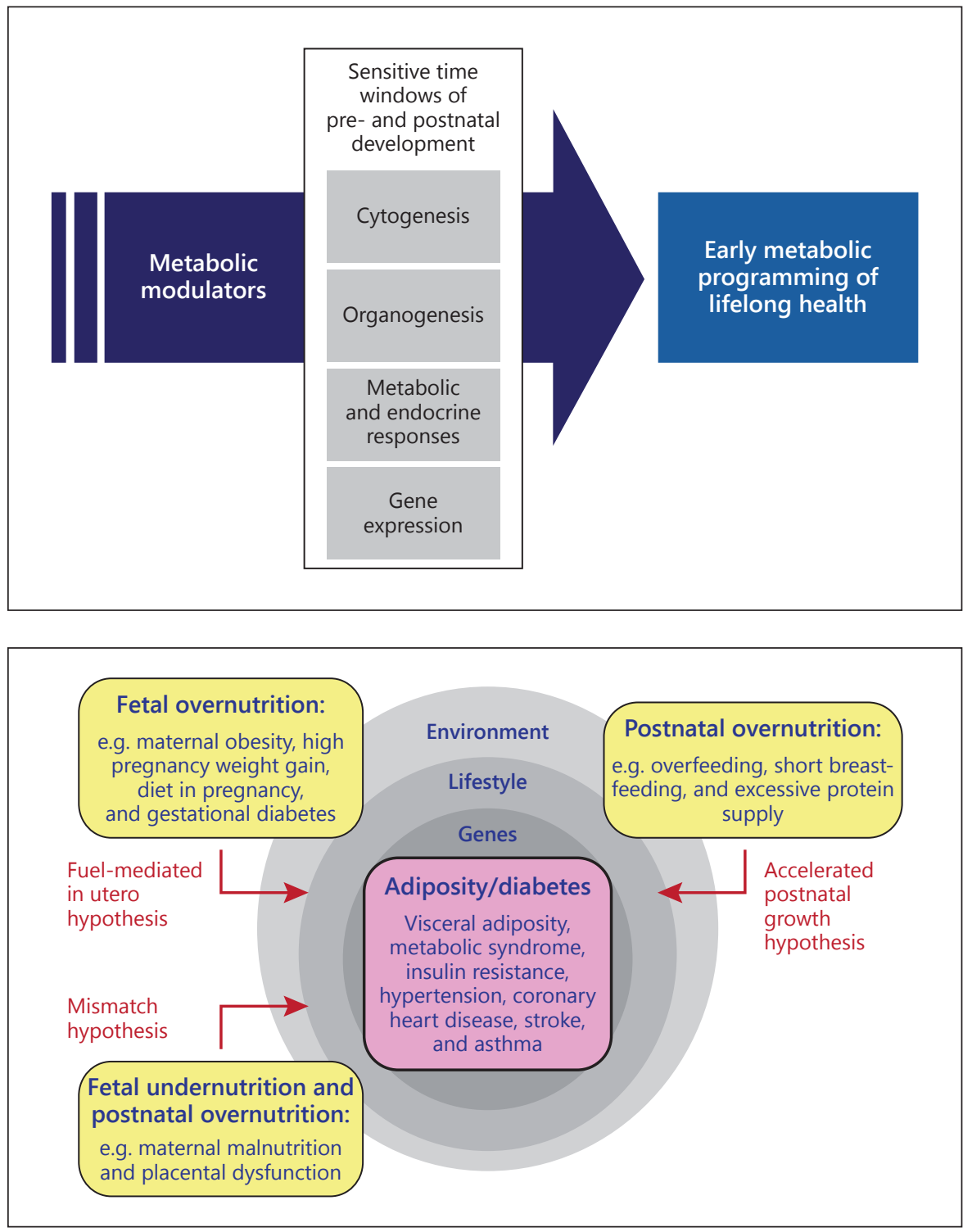

\section{The EarlyNutrition Project and the EarlyNutrition Academy}

The conference was jointly hosted by the EarlyNutrition project and the EarlyNutrition Academy (ENA). The EarlyNutrition project (http://www.project-earlynutrition.eu) is a multinational, multidisciplinary research collaboration and is currently the largest research project worldwide on the developmental origins of health [1]. Researchers from 36 institutions in 15 countries in Europe, the USA, and Australia (table 1) worked together to investigate how nutrition and metabolism during sensitive periods of early developmental plasticity can impact cyto- genesis, organogenesis, and metabolic and endocrine responses, as well as epigenetic effects on gene expression, and thereby modulate later health (fig. 1) [2]. A particular focus is placed on exploration of the developmental origins of obesity, adiposity, and related health outcomes due to the major public health importance of these outcomes and because of particularly convincing evidence of programming effects on adiposity and obesity [3-6]. The EarlyNutrition project is coordinated by the Dr. von Hauner Children's Hospital at the Ludwig Maximilians University of Munich and has a budget of EUR 11.1 million (about USD 15.3 million) funded by the 7th Framework Programme of the European Commission (grant 


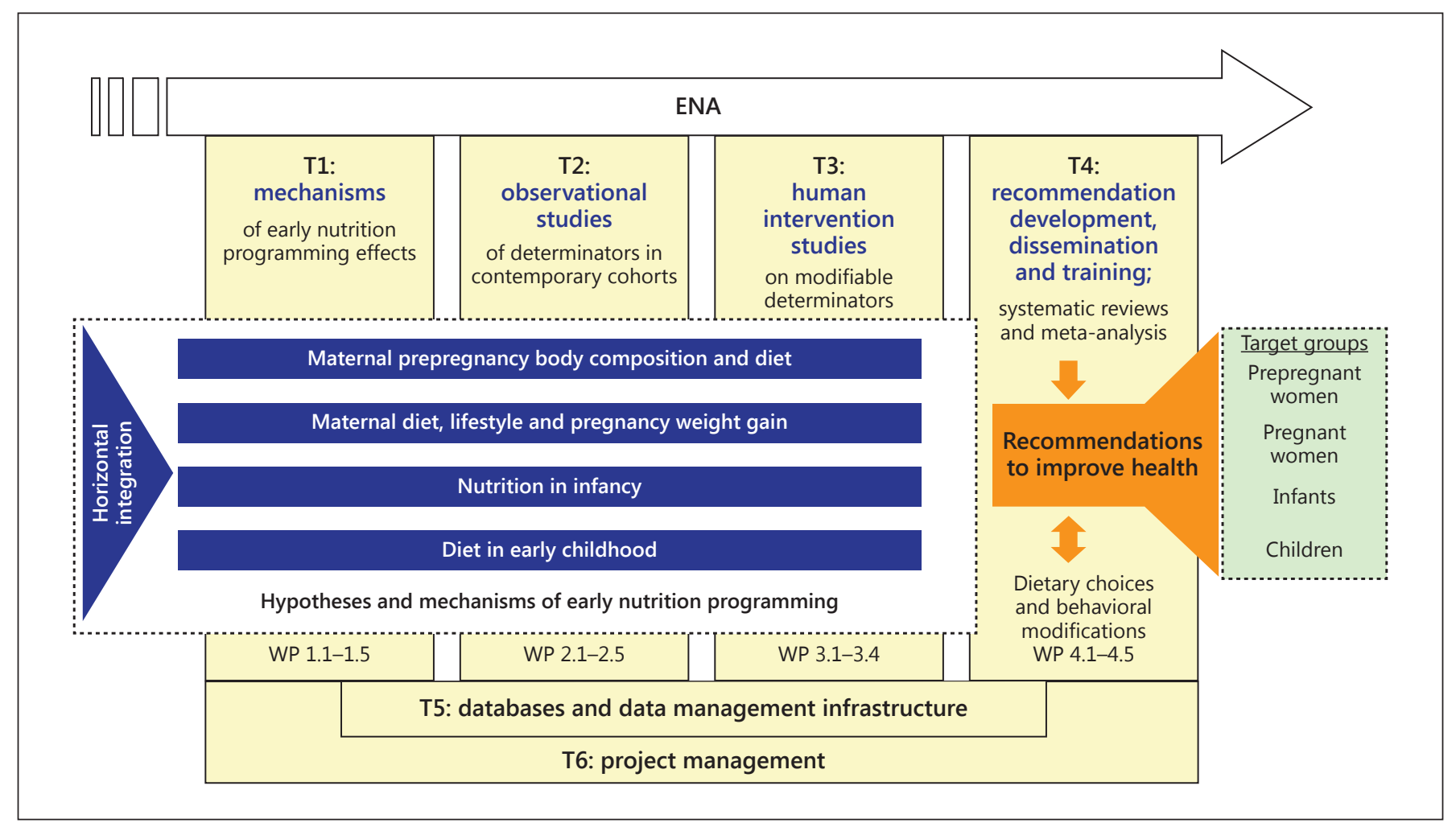

Fig. 3. Structure and elements of the EarlyNutrition project. Copyright: the EarlyNutrition project.

No. FP7-289346-EARLY NUTRITION), with cofounding provided by the Australian National Health and Medical Research Council (NMHMRC), national funding agencies, and support from commercial project partners. In addition, the European Research Council Advanced Grant ERC-2012-AdG - No. 322605 META-GROWTH has provided further support to explore the metabolomics and epigenetic pathways of programming. The work packages of the EarlyNutrition consortium explore the following 3 current key hypotheses regarding the likely causes of the early life origins of adiposity and associated disorders [4] (fig. 2):

(1) the fuel-mediated in utero hypothesis,

(2) the accelerated postnatal growth hypothesis, and

(3) the mismatch of pre- and postnatal growth trajectories hypothesis.

Scientific and technical expertise in placental biology, metabolomics, and epigenetics are brought together to facilitate understanding at the cellular and molecular levels. Refined strategies for intervention in pregnancy and early postnatal life are developed to prevent obesity. Using a basic science program, existing cohort studies, and ongoing and novel intervention studies, the collaborative research projects aim to providing scientific foundations for evidence-based recommendations for optimal early nutrition that take long-term health outcomes into consideration. These recommendations shall focus on 4 target groups, i.e. women before pregnancy, pregnant and breast-feeding women, infants, and young children (fig. 3).

Evidence is produced from animal, placental, and other mechanistic studies including exploration of metabolomic and epigenetic markers (theme 1; T1), prospective cohort studies (T2), and randomized controlled trials in pregnant women and infants (T3) (fig. 3). The total study populations addressed in this project comprise as many as 470,000 individuals. The work in T4 covers scientific strategic integration, the development of evidence-based recommendations including the conduct of systematic reviews, as well as dissemination of those recommendations and exploration of approaches to achieve behavioral changes. The overall aim here is the translational application of scientific results into policy and practice. The project's expected impact comprises the creation of definitive evidence of the effects of early nutrition on health, support for European and global policies in this area, ma- 
jor economic benefits through obesity prevention and value-added nutritional products, and practical recommendations for optimal nutrition in target groups. We aim for wide dissemination through active engagement with stakeholders.

Dissemination is facilitated further by collaboration with the ENA (www.early-nutrition.org), a nonprofit society created by and representing the partners of international research projects that perform studies on food and dietetic products in pregnancy and early childhood, such as the EarlyNutrition project, the NUTRIMENTHE project (www.nutrimenthe.eu), and the Eurreca project (www.eurreca.org). The ENA aims to promote knowledge of human nutrition in early life, to stimulate quality research in this and related areas of science, nutrition, and health, and to disseminate such knowledge. The ENA achieves these goals by holding scientific and training workshops, developing position papers, and organizing training activities such as the EarlyNutrition eAcademy (www.early-nutrition.org/enea.html), an open-access Continuing Medical Education (CME)-accredited elearning platform. Modules in areas related to early nutrition are now available in the English and Mandarin Chinese languages.

\section{Exploration of Mechanisms}

During the first 2 years of EarlyNutrition project work, some major achievements have already been reached. For space reasons, only a few selected ones are highlighted here.

The offspring of obese and diabetic mothers are at an increased risk of being born with excess adiposity as a consequence of their intrauterine environment [7] (fig. 4). Fetal intrauterine exposure to an excessive fetal supply of fuels such as glucose or fatty acids is associated with higher fetal blood and tissue concentrations of glucose and insulin, enhanced fetal growth and body fat deposition, and increased neonatal body weight and body fat content, which predict an increased risk of later offspring obesity [6]. If female offspring later become pregnant, their obesity will again increase the disease risk for their offspring, leading to a transgenerational perpetuation of risk.

The effect of the maternal diet on the fetal metabolism and physiological response is mediated by the placental nutrient uptake and transfer, which was addressed by Larque et al. [8]. Changes in trophoblast nutrient-sensing signaling pathways regulate the cell metabolism and may affect fetal growth and health programming in the off-

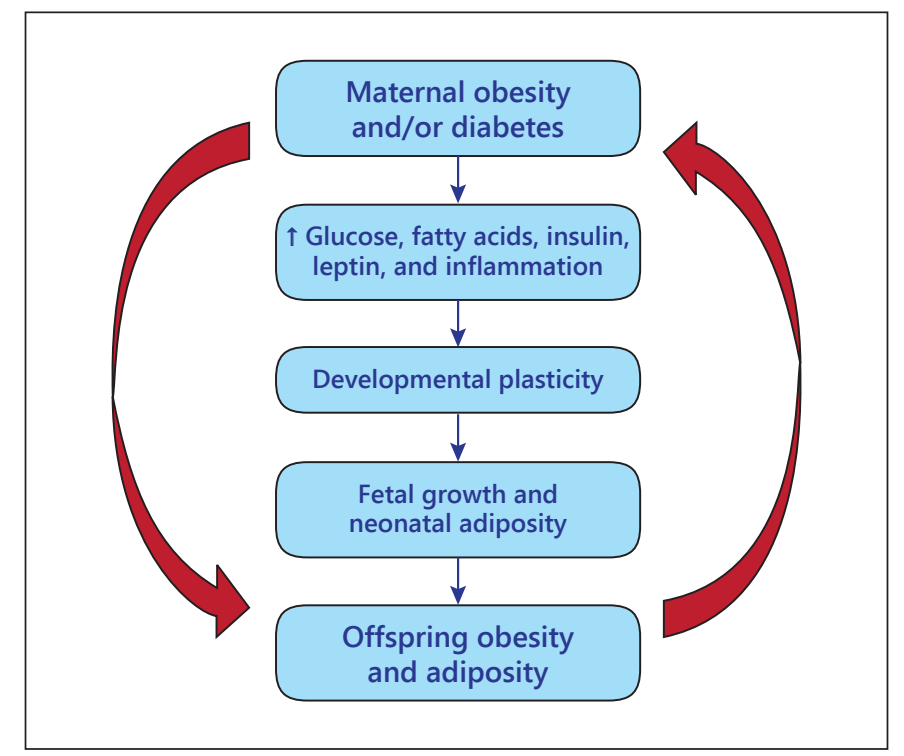

Fig. 4. Obesity and diabetes in pregnant women are associated with an excessive fetal supply of glucose or fatty acids and higher fetal blood and tissue concentrations of glucose and insulin, enhanced fetal growth and body fat deposition, increased neonatal body weight and body fat, and an increased risk of later obesity in the offspring. In female offspring that become pregnant, obesity will again increase the disease risk for their offspring, leading to a transgenerational perpetuation of enhanced risk.

spring. The functionality of the placenta could affect neonatal adiposity and fetal levels of key nutrients, such as long-chain polyunsaturated fatty acids. Insulin, oxygen, and amino acid concentrations may regulate the mammalian target of rapamycin, a nutrient sensor in the human placenta affecting trophoblast metabolism and nutrient delivery to the fetus. Lewis et al. [7] concluded that high plasma levels of specific nutrients in obese and diabetic mothers must be considered important drivers of nutrient transfer to the fetus, resulting in excess fat accretion. Of interest, not all offspring of obese and diabetic mothers are born large for gestational age, which could be due to differential regulation of the placental nutrient transfer required for fetal growth. Understanding the nature of the signals through which the placenta integrates maternal and fetal signals throughout gestation in order to determine the nutrient transfer rate and the placental responses to them is key to understanding the pathology of both fetal growth restriction and macrosomia. The overall effects of the maternal environment on the placenta are the product of its exposures throughout gestation, i.e. the 'placental exposome'. Understanding these environmental influences is important as exposures early 
in gestation (e.g. causing changes in the function of genes involved in nutrient transfer) may determine how the placenta will respond to exposures later in gestation, such as raised maternal plasma glucose or lipid concentrations. Longitudinal studies on the influences on the placenta throughout gestation should make full use of current technologies characterizing placental function, fetal growth, and body composition, which is planned in the EarlyNutrition project. The information evolving from such studies should inform the development of preventive strategies and treatments to optimize prenatal growth in pregnancies at risk of either excess or insufficient nutrient supply and could reduce the risk of chronic disease in later life.

A better understanding of the metabolic pathways that lead to, or are associated with, adiposity and obesity is required for the development of more specific nutritional interventions. In the EarlyNutrition project, a targeted quantitative metabolomics approach platform was established combining liquid chromatography mass spectrometry approaches and an approach using flow injection analysis coupled to triple mass spectrometry, facilitating the analysis of amino acids, acylcarnitines, phospholipids, and nonesterified fatty acids [9-16]. Using this technology, Wahl et al. [17] previously identified 14 serum metabolites with altered concentrations in obese children compared to children of normal weight. Based on these results, Reinehr et al. [40] explored whether weight loss reverses those metabolic alterations. The study included 80 obese children with weight BMI reductions $>0.5 \mathrm{SD}$ following a 1-year treatment program, and another 80 obese children with a stable weight status with the same lifestyle intervention. The results indicated no significant changes in the serum metabolite concentrations of children without weight change. In contrast, children with a substantial weight loss showed a significant increase in glutamine, methionine, the lysophosphatidylcholines LPCaC18:1, LPCaC18:2, and LPCa20:4, and the acyl-alkyl phosphatidylcholine PCaeC36:2. These suggested markers, together with other metabolites associated with obesity, shall be further explored in cohort and intervention studies participating in the EarlyNutrition project.

A further, promising approach is the characterization of epigenetic DNA methylation which might help to better understand the interactions of inherited and environmental factors that shape health outcomes. Teh et al. [18] studied the genotypes and the DNA methylomes of 237 neonates and found 1,423 punctuate regions of the methylomes that were highly variable across individuals, termed variably methylated regions [18]. The authors found that the best explanation for $75 \%$ of the variably methylated regions was the interaction of the genotype with different in utero environments, including maternal smoking, maternal depression, maternal BMI, infant birth weight, gestational age, and birth order, which underlines the importance of considering both fixed genetic variation and environmental factors when interpreting epigenetic variation. An important question is the degree of persistence or fluidity of DNA methylation marks. Martino et al. [19] addressed this question in a recent genome scale study of DNA from buccal epithelium, a relatively homogeneous tissue. One third of the cytosinephophatidyl-guanine sites assayed show dynamic methylation between birth and 18 months of age. Probes located in intragenic regions, enhancers, and low-density cytosine-phophatidyl-guanine promoters were significantly overrepresented with regard to an increase in DNA methylation over time. Based on results in twins, the authors concluded that DNA methylation in buccal epithelium is influenced by nonshared stochastic and environmental factors that could reflect a degree of epigenetic plasticity within an otherwise constrained developmental program. These results emphasize the importance of further studying DNA methylation repeatedly at different ages, which is planned in subjects enrolled into studies that are part of the EarlyNutrition project.

\section{Cohort Studies}

Well-designed and well-conducted contemporary cohort studies are particularly valuable to characterize relevant exposures in early life and their effect sizes on relevant outcomes. In an evaluation of data from the prospective Generation R cohort study on 6,959 mothers and their children, risk factors and maternal, fetal, and childhood consequences of maternal obesity and excessive gestational weight gain were determined [20]. A lower maternal education level, a lower household income, multiparity, and the FTO gene risk allele were associated with an increased risk of maternal obesity (all $p<0.05$ ). Compared to normal weight, maternal obesity was associated with a $~ 3$-fold risk of delivering a large-for-gestational-age infant and a 5-fold risk of childhood obesity. Of interest, compared to prepregnancy overweight and obesity, excessive gestational weight gain had only a limited influence on adverse pregnancy outcomes. This supports previously raised concerns of focusing preventive approaches on restricting weight gain during pregnancy $[21,22]$. 
Table 2. Outcomes of infants born to overweight women in the Australian LIMIT trial, randomized to lifestyle advice or standard care

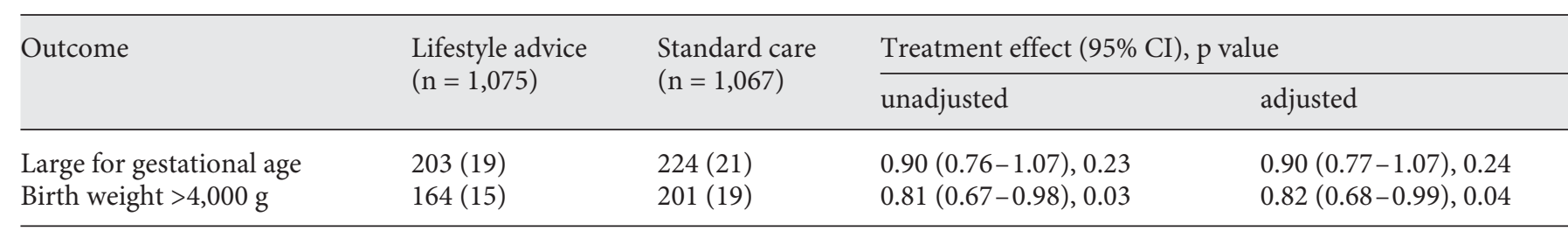

Values are numbers of infants (\%), and treatment effects are unadjusted and adjusted relative risks based on imputed data. Modified from Dodd et al. [39].

Crozier et al. [23] explored the relation of maternal vitamin D status in pregnancy with offspring body composition in women who participated in the Southampton Women's Survey. A lower maternal vitamin D status was associated with a lower fat mass in the offspring at birth but with a greater fat mass at ages 4 and 6 years. In contrast, no such association was found for lean mass, also after for a range of confounding factors including maternal BMI and weight gain in pregnancy. Thus, poor maternal vitamin D levels may play a role in the origins of adiposity, which could be tested in targeted intervention studies.

\section{Randomized Intervention Studies}

Results of randomized controlled trials (RCT) are particularly important for informing policy and practice. So far the number of RCT in the area of developmental programming of obesity has been limited. However, 2 RCT that are part of the EarlyNutrition project recently published rather exciting results.

The Australian LMIT trial enrolled 2,212 women with a singleton pregnancy between 10 and 20 weeks of gestation in 3 hospitals. The women were randomized to standard care or to a lifestyle intervention focusing on regular physical activity and a balanced diet with limited consumption of refined carbohydrates and saturated fats. The intervention was delivered by research staff during 3 face-to-face meetings after enrollment, at 28 weeks' gestation and at 36 weeks' gestation, and it was reinforced by 3 telephone calls at 22, 24, and 32 weeks' gestation. The primary outcome, i.e. the incidence of infants born large for gestational age (birth weight $\geq 90$ th centile for gestation and sex), showed a nonsignificant trend towards a $10 \%$ reduction in the intervention group (table 2 ). However, the intervention did reduce the rate of high birth weights $(>4,000 \mathrm{~g})$, a pre-specified secondary outcome, by almost $19 \%$. Of interest, the intervention did not affect gestational weight gain, which again raises questions regarding the relative importance of restricting weight gain in pregnancy. The results of the LIMIT trial are very encouraging given the fact that a meta-analysis of 20 observational studies found that a high birth weight $(>4,000 \mathrm{~g})$ was linked to a 2 -fold increased risk of later obesity [24]. Similarly, in a prospective cohort study comprising 7,738 children in the USA, a high birth weight $>4,000 \mathrm{~g}$ was present in only $12 \%$ of the population but in $>36 \%$ of the children who were obese at the age of 14 years [25]. The preventive potential of a lifestyle intervention that is very similar to the one applied in the LIMIT trial is currently being evaluated in the UPBEAT randomized trial in the UK [26]. In case of replication of the findings of the Australian LIMIT trial in UPBEAT, one would have a very strong basis for further development and application of such preventive interventions.

In addition to interventions before and during pregnancy, postnatal feeding choices for infants also offer considerable opportunities for obesity prevention. In numerous observational studies, breast-feeding has been found to be associated with an approximately $15-25 \%$ reduced risk of later obesity [27-29]. This apparent preventive effect has been linked to a slightly different growth pattern in breast-fed infant populations compared to infants fed with conventional bottle milks: breast-feeding reduces the likelihood of rapid weight gain in the first 2 years of life, which is associated with an increased risk of later obesity $[1,3,30,31]$. A large European multicenter, double-blind, randomized clinical trial tested the hypothesis that a reduced protein content in infant formula - achieving levels more similar to those typically found in human breast milk - can reduce both high early weight gain and later obesity. Some 1,678 healthy infants were enrolled. The formula-fed infants $(\mathrm{n}=1,090)$ were randomly assigned to receive double-masked formula with a higher protein (HP) or a lower protein (LP) content, respectively, during the first year of life. A group of infants fully breast-fed for at least 3 months $(\mathrm{n}=588)$ was followed as an observa- 
Table 3. The marked effect of infant feeding on the obesity risk at an early school age (6 years) in the double-blind randomized European Childhood Obesity Project Trial

\begin{tabular}{llll}
\hline $\begin{array}{l}\text { Obesity (LP group), } \\
\%\end{array}$ & $\begin{array}{l}\text { Obesity (HP group), } \\
\%\end{array}$ & $\begin{array}{l}\text { Adjusted relative risk } \\
(95 \% \text { CI }), \text { p value }\end{array}$ & $\begin{array}{l}\text { Obesity (breast- } \\
\text { fed infants), } \%\end{array}$ \\
\hline 4.4 & 10 & $2.87(1.22-6.75), 0.016$ & 2.9 \\
\hline
\end{tabular}

Feeding of the infant with a follow-up formula with a reduced protein content but an equal energy content significantly reduced the risk of obesity. As a reference, a nonrandomized group of children who were fully breast-fed for at least 3 months was followed. The percentages of obese children at age of 6 years in the different feeding groups are shown. Modified from Weber et al. [33]. tional reference group. Weight and BMI gain from birth to age 2 years were higher in the HP group compared to the LP group, while the LP and breast-fed children had similar weights and BMI at age 2 years [32]. At the age of 6 years, the children in the HP group had a significantly higher BMI than those in the LP group (estimated difference $0.51 ; 95 \%$ CI $0.13-0.90 ; p=0.009$ ) [33]. The adjusted risk of obesity at age 6 years was 2.87 -fold higher in the HP group than in the LP group ( $\mathrm{p}=0.016)$ (table 3$)$. The results of this large RCT indicate that avoidance of infant foods that provide excessive protein intakes is an effective strategy to reduce childhood obesity.

\section{Systematic Reviews as the Basis for Developing Recommendations}

As part of the work performed in the theme of the project (fig. 3), systematic reviews are performed to prepare the basis for the later development of recommendations. Sui et al. [34] evaluated RCT comparing supervised antenatal exercise intervention with routine standard antenatal care in women who were overweight or obese during pregnancy [34]. Six RCT and 1 quasi-randomized trial were included, involving a total of 276 women. The authors concluded that supervised antenatal exercise intervention reduces gestational weight gain, but the effects on maternal and infant health remain uncertain.

Based on the hypothesis that the intrauterine environment is an independent factor in obesity development, a systematic evaluation was performed to test associations of offspring BMI or adiposity with maternal or paternal BMI [35]. Three studies provided a direct comparison of parent-offspring associations, with a statistically stronger maternal influence found only in one cohort, while in one additional small study the maternal BMI was a strong predictor of childhood obesity. Therefore, currently there is only limited evidence that the maternal BMI is a stronger predictor of offspring obesity than the paternal BMI. As part of the work in T4, further systematic reviews are being conducted to assess the current recommendations for pregnant and lactating women and for infants and young children.

\section{Position Papers}

The EarlyNutrition project and the ENA have also developed review and position papers on some key questions which are relevant to the core topics of the project. Given that body composition is a central endpoint of studies across the themes of the project, a workshop was held to review and discuss methods to assess body composition in the target groups of the project [36]. The key goals of the workshop were to discuss approaches for assessment of growth and body composition from pregnancy to adolescence, to summarize conclusions, and to prepare a framework for research in this area in the EarlyNutrition project. It was concluded that there is a pressing need to harmonize methodologies for the assessment of body composition, recognizing that each technique has advantages and limitations. Essential core measurements across studies assessing early growth and body composition were identified, including weight, length, BMI, waist and mid-upper arm circumference, subscapular and triceps skinfold thicknesses, and bioelectrical impedance analysis. In research settings with access to more sophisticated technologies, additional methods could include dual-energy X-ray absorptiometry, peripheral quantitative computer tomography, ultrasound assessment of regional body fat, MRI, air displacement plethysmography, and deuterium dilution. These provide enriched data to answer research questions in greater depth but also increase costs. Where overall wholebody composition is the primary outcome measure, air displacement plethysmography or tracer dilution should 
be used whenever possible. Where the regional distribution of body fat is of greater interest, an imaging technique such as MRI is preferred.

The EarlyNutrition project performs clinical research in pregnant women, infants, and children in collaboration with academic centers and commercial enterprises, which is sometimes discussed controversially. Therefore, a review of the available literature was performed and an expert workshop was held to evaluate public-private collaboration in this area of research and to provide recommendations [37]. It was concluded that clinical research collaborations between academic investigators and commercial enterprises are encouraged by universities, public funding agencies, and governmental organizations, among other reasons because there is an urgent need to obtain evidence on the effects, safety, and benefits of drugs and other commercial products and services. However, the credibility and value of results obtained through public-private research collaborations have often been questioned, partly because many examples of inappropriate research practices have become known. Since clinical research in pregnant and breast-feeding women, and in infants and children, raises sensitive scientific, ethical, and societal questions, the application of particularly high standards is required. Recommendations were provided for the conduct of public-private research collaborations in these populations, which should contribute to more reliable, credible, and acceptable results of commercially sponsored trials and to a reduction of the currently existing credibility gap [37].

The ENA also organized and sponsored a global expert consultation to provide scientific recommendations on the compositional requirements of follow-up formula for use in infancy, which has informed the discussions on the development of a global standard in this area by the Codex Alimentarius Commission of the Food and Agriculture Organization and the World Health Organization [38].

\section{Conclusions}

The EarlyNutrition project has successfully established itself during its first 2 project years as a very strong platform for collaborative research on the programming effects of nutritional and other events in the early stages of life on long-term health, well-being, and performance in adulthood. The first results that have become available already at this early stage of the project point to great opportunities for health prevention strategies by implementing dietary and lifestyle modifications, with large effect sizes. Position papers and recommendations have achieved a wider impact. Many more results are expected to become available during the further evolution of the project, which should support the development of improved recommendations and policies on nutrition and lifestyle choices before and during pregnancy, and for infancy and early childhood and related policies.

\section{Acknowledgements}

The work reported herein was carried out with partial financial support from the Commission of the European Communities, 7 th Framework Programme, contract FP7-289346-EARLY NUTRITION, and European Research Council Advanced Grant ERC2012-AdG - No. 322605 META-GROWTH. This paper does not necessarily reflect the views of the Commission and in no way anticipates the future policy in this area.

\section{Disclosure Statement}

The authors declare no conflicts of interest in relation to the content of this paper.

\section{References}

1 Koletzko B, Brands B, Poston L, Godfrey K, Demmelmair H; Early Nutrition Project: Early nutrition programming of long-term health. Proc Nutr Soc 2012;71:371-378.

2 Brands B, Koletzko B: Frühe Ernährung und langfristiges Adipositasrisiko: Chancen für die pädiatrische Prävention. Monatsschr Kinderheilkd 2012;160:1096-1102.

-3 Brands B, Demmelmair H, Koletzko B; EarlyNutrition Project: How growth due to infant nutrition influences obesity and later disease risk. Acta Paediatr 2014;103:578-575.
Koletzko B, Symonds M, Olsen SF; Early Nutrition Programming Project; Early Nutrition Academy: Programming research - where are we and where do we go from here? Am J Clin Nutr 2011;94:2036S-2043S.

5 Berti C, Cetin I, Agostoni C, Desoye G, Devlieger R, Emmett PM, Ensenauer R, Hauner H, Herrera E, Hoesli I, Krauss-Etschmann S, Olsen SF, Schaefer-Graf U, Schiessl B, Symonds ME, Koletzko B: Pregnancy and infants' outcome: nutritional and metabolic implications. Crit Rev Food Sci Nutr 2014, Epub ahead of print.
6 Symonds ME, Mendez MA, Meltzer HM, Koletzko B, Godfrey K, Forsyth S, van der Beek EM: Early life nutritional programming of obesity: mother-child cohort studies. Ann Nutr Metab 2013;62:137-145.

7 Lewis RM, Demmelmair H, Gaillard R, Godfrey KM, Hauguel-de Mouzon S, Huppertz B, Larque E, Saffery R, Symonds ME, Desoye G: The placental exposome: placental determinants of fetal adiposity and postnatal body composition. Ann Nutr Metab 2013;63:208215 
8 Larque E, Ruiz-Palacios M, Koletzko B: Placental regulation of fetal nutrient supply. Curr Opin Clin Nutr Metab Care 2013;16: 292-297.

-9 Uhl O, Glaser C, Demmelmair H, Koletzko B: Reversed phase LC/MS/MS method for targeted quantification of glycerophospholipid molecular species in plasma. J Chromatogr B Analyt Technol Biomed Life Sci 2011;879: 3556-3564.

10 Hellmuth C, Uhl O, Segura-Moreno M, Demmelmair H, Koletzko B: Determination of acylglycerols from biological samples with chromatography-based methods. J Sep Sci 2011;34:3470-3483.

11 Uhl O, Demmelmair H, Klingler M, Koletzko B: Changes of molecular glycerophospholipid species in plasma and red blood cells during docosahexaenoic acid supplementation. Lipids 2013;48:1103-1113.

12 Harder U, Koletzko B, Peissner W: Quantification of 22 plasma amino acids combining derivatization and ion-pair LC-MS/MS. J Chromatogr B Analyt Technol Biomed Life Sci 2011;879:495-504.

13 Niesser M, Harder U, Koletzko B, Peissner W: Quantification of urinary folate catabolites using liquid chromatography-tandem mass spectrometry. J Chromatogr B Analyt Technol Biomed Life Sci 2013;929: 116-124.

14 Hellmuth C, Koletzko B, Peissner W: Aqueous normal phase chromatography improves quantification and qualification of homocysteine, cysteine and methionine by liquid chromatography-tandem mass spectrometry. J Chromatogr B Analyt Technol Biomed Life Sci 2011;879:83-89.

15 Hellmuth C, Weber M, Koletzko B, Peissner $\mathrm{W}$ : Nonesterified fatty acid determination for functional lipidomics: comprehensive ultrahigh performance liquid chromatographytandem mass spectrometry quantitation, qualification, and parameter prediction. Anal Chem 2012;84:1483-1490.

16 Hellmuth C, Demmelmair H, Schmitt I, Peissner W, Bluher M, Koletzko B: Association between plasma nonesterified fatty acids species and adipose tissue fatty acid composition. PLoS One 2013;8:e74927.

-17 Wahl S, Yu Z, Kleber M, Singmann P, Holzapfel C, He Y, Mittelstrass K, Polonikov A, Prehn C, Romisch-Margl W, Adamski J, Suhre K, Grallert H, Illig T, Wang-Sattler R, Reinehr T: Childhood obesity is associated with changes in the serum metabolite profile. Obes Facts 2012;5:660-670.

-18 Teh AL, Pan H, Chen L, Ong ML, Dogra S, Wong J, Macisaac JL, Mah SM, McEwen LM, Saw SM, Godfrey KM, Chong YS, Kwek K, Kwoh CK, Soh SE, Chong MF, Barton S, Karnani N, Cheong CY, BuschdorfJP, Stunkel W, Kobor MS, Meaney MJ, Gluckman PD, Holbrook JD: The effect of genotype and in utero environment on inter-individual variation in neonate DNA methylomes. Genome Res 2014;24:1064-1074.
19 Martino D, Joo JE, Sexton-Oates A, Dang T, Allen K, Saffery R, Prescott S: Epigenomewide association study reveals longitudinally stable DNA methylation differences in CD4+ $\mathrm{T}$ cells from children with IgE-mediated food allergy. Epigenetics 2014, E-pub ahead of print.

20 Gaillard R, Durmus B, Hofman A, Mackenbach JP, Steegers EA, Jaddoe VW: Risk factors and outcomes of maternal obesity and excessive weight gain during pregnancy. Obesity (Silver Spring) 2013;21:1046-1055.

21 National Institute for Health and Care-Excellence: Weight Management before, during and after Pregnancy (PH27). London, NICE, 2010.

22 Koletzko B, Bauer CP, Bung P, Cremer M, Flothkotter M, Hellmers C, Kersting M, Krawinkel M, Przyrembel H, Rasenack R, Schafer T, Vetter K, Wahn U, Weissenborn A, Wockel A: German national consensus recommendations on nutrition and lifestyle in pregnancy by the 'healthy start - young family network'. Ann Nutr Metab 2013;63:311-322.

23 Crozier SR, Harvey NC, Inskip HM, Godfrey KM, Cooper C, Robinson SM: Maternal vitamin $\mathrm{d}$ status in pregnancy is associated with adiposity in the offspring: findings from the Southampton Women's Survey. Am J Clin Nutr 2012;96:57-63

-24 Yu ZB, Han SP, Zhu GZ, Zhu C, Wang XJ, Cao XG, Guo XR: Birth weight and subsequent risk of obesity: a systematic review and meta-analysis. Obes Rev 2011;12:525-542.

25 Cunningham SA, Kramer MR, Narayan KM: Incidence of childhood obesity in the united states. N Engl J Med 2014;370:403-411.

26 Briley AL, Barr S, Badger S, Bell R, Croker H, Godfrey KM, Holmes B, Kinnunen TI, Nelson SM, Oteng-Ntim E, Patel N, Robson SC, Sandall J, Sanders T, Sattar N, Seed PT, Wardle J, Poston L: A complex intervention to improve pregnancy outcome in obese women: the upbeat randomised controlled trial. BMC Pregnancy Childbirth 2014;14:74.

27 Weng SF, Redsell SA, Swift JA, Yang M, Glazebrook CP: Systematic review and metaanalyses of risk factors for childhood overweight identifiable during infancy. Arch Dis Child 2012;97:1019-1026.

28 Arenz S, Ruckerl R, Koletzko B, von Kries R: Breast-feeding and childhood obesity - a systematic review. Int J Obes Relat Metab Disord 2004;28:1247-1256.

29 Koletzko B, von Kries R, Monasterolo RC, Subias JE, Scaglioni S, Giovannini M, Beyer J, Demmelmair H, Anton B, Gruszfeld D, Dobrzanska A, Sengier A, Langhendries JP, Cachera MF, Grote V: Infant feeding and later obesity risk. Adv Exp Med Biol 2009;646: $15-29$.

30 Grote V, Theurich M, Koletzko B: Do complementary feeding practices predict the later risk of obesity? Curr Opin Clin Nutr Metab Care 2012;15:293-297.

31 Druet C, Stettler N, Sharp S, Simmons RK, Cooper C, Smith GD, Ekelund U, Levy-
Marchal C, Jarvelin MR, Kuh D, Ong KK: Prediction of childhood obesity by infancy weight gain: an individual-level meta-analysis. Paediatr Perinat Epidemiol 2012;26:19-26.

32 Koletzko B, von Kries R, Closa R, Escribano J, Scaglioni S, Giovannini M, Beyer J, Demmelmair H, Gruszfeld D, Dobrzanska A, Sengier A, Langhendries JP, Rolland Cachera MF, Grote V: Lower protein in infant formula is associated with lower weight up to age $2 \mathrm{y}$ : a randomized clinical trial. Am J Clin Nutr 2009;89:1836-1845.

33 Weber M, Grote V, Closa-Monasterolo R, Escribano J, Langhendries JP, Dain E, Giovannini M, Verduci E, Gruszfeld D, Socha P, Koletzko B; European Childhood Obesity Trial Study Group: Lower protein content in infant formula reduces BMI and obesity risk at school age: follow-up of a randomized trial. Am J Clin Nutr 2014;99:1041-1051.

34 Sui Z, Grivell RM, Dodd JM: Antenatal exercise to improve outcomes in overweight or obese women: a systematic review. Acta Obstet Gynecol Scand 2012;91:538-545.

35 Patro B, Liber A, Zalewski B, Poston L, Szajewska H, Koletzko B: Maternal and paternal body mass index and offspring obesity: a systematic review. Ann Nutr Metab 2013;63:3241.

36 Ward LC, Poston L, Godfrey KM, Koletzko B: Assessing early growth and adiposity: report from an EarlyNutrition Academy workshop. Ann Nutr Metab 2013;63:120-130.

37 Koletzko B, Benninga MA, Godfrey KM, Hornnes PJ, Kolacek S, Koletzko S, Lentze MJ, Mader S, McAuliffe FM, Oepkes D, Oddy WH, Phillips A, Rzehak P, Socha P, Szajewska $\mathrm{H}$, Symonds ME, Taminiau J, Thapar N, Troncone R, Vandenplas Y, Veereman G: Public-private collaboration in clinical research during pregnancy, lactation, and childhood: joint position statement of the Early Nutrition Academy and the European Society for Pediatric Gastroenterology, Hepatology, and Nutrition. J Pediatr Gastroenterol Nutr 2014;58:525-530.

38 Koletzko B, Bhutta ZA, Cai W, Cruchet S, El Guindi M, Fuchs GJ, Goddard EA, van Goudoever JB, Quak SH, Kulkarni B, Makrides M, Ribeiro H, Walker A: Compositional requirements of follow-up formula for use in infancy: recommendations of an international expert group coordinated by the Early Nutrition Academy. Ann Nutr Metab 2013;62:44-54.

39 Dodd JM, Turnbull D, McPhee AJ, Deussen AR, Grivell RM, Yelland LN, Crowther CA, Wittert G, Owens JA, Robinson JS: Antenatal lifestyle advice for women who are overweight or obese: LIMIT randomised trial. BMJ 2014;348:g1285

40 Reinehr T, Wolters B, Knop C, Lass N, Hellmuth C, Harder U, Peissner W, Wahl S, Grallert $\mathrm{H}$, Adamski J, Illig T, Prehn C, Yu Z, Wang-Sattler R, Koletzko B: Changes in the serum metabolite profile in obese children with weight loss. Eur J Nutr 2014, Epub ahead of print. 